\title{
A randomized controlled trial of rectal analgesia diclofenac sodium for relief of perineal pain following child birth
}

\author{
Dasanayake DLW ${ }^{1}$
}

\begin{abstract}
Objectives: To evaluate rectal diclofenac sodium in the relief of perineal pain after trauma during childbirth.

Design: A randomized, double blind trial.

Setting: The obstetric department (ward 21), Professorial Unit, Colombo South Teaching Hospital, Kalubowila.
\end{abstract}

Population: Women with an episiotomy or any degree of perineal tears including vestibular tears, which required suturing.

Method: Women were randomly allocated to either diclofenac sodium or placebo suppositories (Anusol), using a random - number table. Treatment packs contained two, diclofenac sodium $100 \mathrm{mg}$ and diclofenac sodium $50 \mathrm{mg}$ suppositories or two placebo suppositories, The first (diclofenac sodium100mg or placebo) was inserted when suturing was completed, and the second ( $50 \mathrm{mg}$ diclofenac sodium or placebo) 12 hours after birth. Women were asked to indicate their degree of perineal pain at 24 hours after birth, using $10 \mathrm{~cm}$ visual analogue scale.

Main outcome measure: Pain score at 24 hours after birth.

Results: A total of 169 women were recruited, with 84 randomized to diclofenac sodium suppositories and 85 to placebo. Women in the diclofenac sodium group were significantly less likely to experience pain within 24 hours of delivery (percentage of mean pain score reduction , 45\%, $\mathrm{P}<.001$ ) compared with those who received placebo.

Conclusions: The use of rectal diclofenac sodium is a simple and effective method of reducing the pain experienced by women following perineal trauma within the first 24 hours after childbirth.

\section{INTRODUCTION}

Perineal damage can cause significant maternal morbidity both immediate and long term. Morbidity associated with child birth may affect a woman's physical, psychological and social wellbeing. A vast majority of morbidity associated with perineal trauma is under reported ${ }^{1}$. Perineal discomfort may disrupt breast feeding, family life and sexual relationship ${ }^{2}$. Majority of mothers experience perineal pain and

\footnotetext{
1 Senior Lecturer/Specialist in Obstetrics \& Gynaecology, Department of Obstetrics \& Gynaecology, Faculty of Medicine, University of Ruhuna, Galle.
}

\section{Correspondence: DLW Dasanayake}

E-mail: lanka.dasanayake@yahoo.com

Competing interests: None discomfort for 10 to 12 days following childbirth, which is more severe in the immediate postnatal period and some of them will continue to have long term pain for 3 to 8 months following delivery ${ }^{1,3}$. Other long term morbidities associated with perineal trauma is superficial dispareunia, fecal incontinence and some degree of urinary incontinence ${ }^{3,4,5}$. Trauma to perineum is very painful and distressing to mothers and it has been associated with restricted mobilization, acute urinary retention, constipation, disturbance in breastfeeding etc.

Vast majority of perineal trauma is due to intentionally made episiotomy to facilitate vaginal delivery. Episiotomy rates vary considerably in various countries according to individual practices and policies of staff and institutions. Overall rates of episiotomy in different countries range from $8 \%$ to $99 \%{ }^{6,7}$. In Sri Lanka almost all primipara and most of the multipara experience episiotomy in hospital practice.

Post partum pain relief is one of the ignored aspects following childbirth due to under estimation. As almost all mothers experience perineal pain in different severity following child birth, the provision of safe and effective pain relief in modern healthcare practice is an essential component in obstetrics as mothers do not accept perineal pain following childbirth. Currently in Sri Lanka, there is no routine practice of perineal pain relief protocol, following child birth.

The provision of pain relief for perineal trauma has several therapies in clinical practice, which include rectal analgesics, oral analgesics, local anesthetics, parenteral analgesics, therapeutic ultrasound and non pharmacological applications such as baths and ice packs ${ }^{8}$. Simple oral analgesics such as paracetamol and Paracetamol + Codeine can be used as pain relief for mild pain ${ }^{9}$. But efficacy is poor for moderate to severe pain following more extensive trauma such as 3rd and 4th degree perineal tears. Simple analgesics have a place when combined with other pharmacological agents for additive effect ${ }^{10}$. NonSteroidal-Anti-Inflammatory-Drugs (NSAID's) are important analgesics for mild to moderate pain especially associated with physical trauma to tissue with acute inflammation ${ }^{11}$. A wide range of drugs are available with various efficacies administered in different routes; local/oral/rectal/ parenteral. Local infiltration of anesthetic agents such as lignocaine has a limited place for perineal pain relief due to its short lasting activity. Parenteral agents such as morphine and pethidine are associated with unwanted side effects e.g. drowsiness, respiratory depression, difficulty in breastfeeding etc. Therefore these agents are not used for routine perineal pain relief. 
In general medical care, the rectal route of analgesics administration has been favoured with good compliance when oral preparations cause gastric irritation, nausea and vomiting ${ }^{12}$. As the rectal mucosa have a rich vascular, and lymph supply, absorption of drugs is fast and analgesic effect occurs in a shorter period than oral route. Compared to oral administration of drugs, first pass metabolism is avoided in rectal administration ${ }^{11}$.

Rectal diclofenac sodium is an effective, cheep, widely available and safe analgesic agent for pain relief. Studies assessing the efficacy of rectal analgesics in post-operative pain relief have indicated significant reduction of pain experianced ${ }^{12}$, and reduced requirement of additional analgesia ${ }^{13,14}$, although evidence of efficacy and safety of rectal analgesics in perineal pain relief is lacking ${ }^{15}$. The aim of this study was to evaluate rectal diclofenac sodium in relief of perineal pain after trauma during childbirth.

\section{METHOD}

A randomized, double blind controlled trial was carried out in the Obstetrics department, Professorial Unit, Colombo South Teaching Hospital (CSTH), Kalubowila, from 1st of October 2005 to 1st of February 2006. Ethical approval was obtained from Ethics and Research Committee of CSTH.

The minimum sample size calculation was based on previous research carried out by Corkhill et $\mathrm{al}^{16}$, which showed a mean pain score of 43.5 (SD 21.8) using 101 points numerical rating scale for perineal pain, with rectal analgesia, to detect a clinically significant reduction in pain score from 43.5 to 32.6 in visual analogue scale). It is necessary to recruit 168 subjects to trial (5\% level of significance with $90 \%$ power).

Study information was provided to potentially eligible women with the period of gestation greater than 37 weeks admitted to the unit for vaginal delivery after obtaining their informed consent. Eligible women were randomly allocated following delivery to either diclofenac sodium group or placebo suppository group using random number table. The randomisation schedules were prepared by a researcher not involved in patient care using random number table. Perineal repair or episiotomy suturing were done by senior registrar or registrar or house officer using polyglycolic acid (vicryl) by subcuticular suturing technique. Treatment pack contained $100 \mathrm{mg}$ and 50mg diclofenac sodium, and placebo (Anusol suppositories, which is having least analgesic action in the perineum), 1st diclofenac sodium $100 \mathrm{mg}$ suppository or placebo was inserted by midwife when suturing completed and the second (50 $\mathrm{mg}$ diclofenac sodium or placebo) 12 hours after birth. The women involved in the study were blinded to the allocated treatment groups. Data collection sheets were completed prior to discharge from the hospital at 24 hours after birth by recall, pain score (using ten centimeter visual analogue scale) associated with resting, walking, sitting, and squatting. The patients who complain more pain were prescribed other analgesics (Paracetamol). Ethical approval was obtained from the research and ethical committee of the Colombo South Teaching Hospital. Informed consent has been taken from all the participants. Those who are not willing to be included were given due medical care without any discrimination.

Data were entered into a data collection sheet in the ward and confidentially stored in an ongoing electronic database. Statistical test of significance was done to analyze the result with the help of a standard statistical package, SPSS 2006. Outcome analysis has been done by intention to treat with the use of parametric test ( $\mathrm{t}$ test).

\section{RESULT}

During this study period, a total of 532 women gave vaginal birth at the professorial obstetric unit, Colombo South Teaching Hospital (CSTH) and sustained perineal trauma requiring suturing during child birth. A total of 235 potentially eligible women were approached in the antenatal period for participation in the trial, and 201 (85\%) women provided provisional informed consent, of those women 169 became eligible after birth. All 169 women were included in the analysis; with 84 randomized to receive diclofenac sodium suppositories and 85 women received the placebo. The two group were well balanced for demographic characteristics at the trial entry and labour and birth outcomes as well as perineal repair technique. Study outcome data were available from $98 \%$ of women at 24 hours.

\begin{tabular}{|lcc|}
\hline & Table 1: Basic characteristics of subjects & \\
\hline & Diclofenac Group ( $\mathrm{n}=84)$ & Placebo Group $(\mathrm{n}=85)$ \\
\hline Age & $28.2(\mathrm{yrs})$ & $27.9(\mathrm{yrs})$ \\
\hline Gestational age & $39 \mathrm{w}+$ od & $38+2 \mathrm{~d}$ \\
\hline Parity 1 & 35 & 33 \\
\hline \multicolumn{1}{|c|}{1} & 49 & 52 \\
\hline Birth Weight & $2.81(\mathrm{~kg})$ & $2.94(\mathrm{~kg})$ \\
\hline Induction & 31 & 43 \\
\hline Augmentation & 53 & 42 \\
\hline Duration of labour & $4 \mathrm{hrs} \& 50 \mathrm{~min}$ & 74 \\
\hline MOD ; NVD & 72 & 11 \\
\hline \multicolumn{1}{|c|}{ ID } & 12 & $\mathrm{hrs}$ in \\
\hline
\end{tabular}




\begin{tabular}{|lcccc|}
\hline \multicolumn{5}{c|}{ Table 2: Pain Score at 24 hours after delivery } \\
\hline & Number & Mean & SD & SEM \\
\hline Placebo & 85 & 0.45 & 0.15 & 0.16 \\
\hline Diclofenac Sodium & 84 & 0.25 & 0.11 & 0.12 \\
\hline $\mathrm{P}<0.001$ & & & & \\
\hline
\end{tabular}

Using visual analogue scale, women in the diclofenac sodium group experienced statistically significantly less pain during first 24 hours after birth, when compared with those women who received placebo. Percentage of mean reduction of pain was $45 \%$.

\section{DISCUSSION}

This randomized controlled trial was designed to assess relief of perineal pain due to perineal trauma following childbirth. The research was embarked in an obstetric unit where almost all primi mothers and most of multiparous mothers have had episiotomy during childbirth. Random allocation generated two groups of women, who were similar in several demographic characteristics and other aspects, what could contribute for severity of perineal pain. Both treatment and placebo groups strictly adhered to treatment protocol. Two women from each group defaulted during completion of data collection, but data analysis included whole number, 169 as a policy of intention to treat.

It clearly showed from this study, use of diclofenac sodium suppositories were effective in reducing perineal pain at 24 hours after childbirth.

Perception of pain by women is subjective and the use of analgesia will be influenced by many factors in addition to the level of pain experienced. These finding may influence a policy of regular analgesia being offered and accepted on a routine basis to the women in the postnatal period while in the hospital.

The half-life of diclofenac sodium in plasma is one to two hours after oral administration. After rectal administration, absorption is complete in less than 40 minutes. While the half life is longer after rectal administration, the total area under the curve is similar for both preparations. Diclofenac sodium is almost completely protein bound, \& as a result minimum amount of the drug is excreted in the breast milk - an important consideration for women who are breastfeeding. While rectal suppositories may be effective in reducing pain experienced after childbirth, drug effectiveness becomes a secondary consideration, if women express reluctance to the rectal route of administration. There appears to be clear advantages in using diclofenac sodium suppositories to provide short team pain relief for perineal pain after childbirth.

\section{CONCLUSION}

The use of rectal diclofenac sodium is a simple and effective method of the reducing pain experienced by women following perineal trauma within the 1st 24 hours after childbirth.

\section{ACKNOWLEDGEMENTS}

I sincerely pay my gratitude to Dr. Rukshan Fernandopulle who directed me to make this endeavour successful and wish to thank Dr. Ananda Wijesiri (Department of Community Medicine, University of Ruhuna) for his invaluable help in data management and statistical analysis.

\section{REFERENCES}

01. Glazener CMA, Abdalla M, Stroud P, Naii S, Templeton A, Russell IT Postnatal morbidity. Extend, course, prevention and treatment. Br J Obstet Gynaecol,1995; 102: 286-7.

02. Sleep J. Perineal care: a series of 5 randomized control trials, In :Robinson S, Thomson A, Editors. Midwives Research and Child-birth. London Chapman and Holl. 1991 : p 199-251.

03. Sleep J, Grant J, Garcia J, Elbourne D, Spencer JAD, Chalmers I, B West
Berkshire perineal management trial BMJ 1984; 289: 587-590

04. Sleep J, Grant A. Pelvic floor exercise in post natal care. BJ. Midwifery $1987 ; 158$ 64.

05. Sultan AH,Kamm MA, Hudson CN. Ana sphincter Disruption during vaginal delivery. N. Engl J Med. 1993; 329: 1905 -11 .

06. Renfew M.T. Hannah W, Albert L, Floyed E. Practices that minimize trauma to the genital track in the child birth : A systematic review of the Literatur. Birth $1998 ; 25: 143-160$

07. Audit Commission, First class delivery: Improving maternity services in England and wales. London : Audit Commission Publication 1997

08. Grant A, Sleep J. Relief of Perineal Pain and discomfort after child birth. Chalmers I, Enkim M, Keirse MJNC editors effective care in pregnancy and childbirth. Oxford university Press 1989 1347-1358

09. Bennet P.N, Brown M.J, Minaur N.J. Inflammation, Arthritis and NSAIDS. Clinical Pharmacology. 2003; 15(19):279-298.

10. Bennet P.N, Brown M.J, Grewa J. Pain and Analgesics. Clinical Pharmacology. 2003; 17(19):319-325.

11. Bennet P.N, Brown M.J, General pharmacology. Clinical Pharmacology. 2003; 7(19):104-109.

12. Nissen I, Jensen KA, Indomethacin in management of postoperative pain. $\mathrm{Br} J$ Anaesth 1992 ; 69(3):304-306.

13. Simms C, Johnson C, Bergesion R, Delfos S. J. Avraamides EA. Rectal Indometacin for analgesics after appendectomy in children. Anaesth intensive care, 1994; 22(3) : 72-275.

14. Scott RM, Jennings PN. Rectal analgesia after Abdominal Hysterectomy. Aust NZJ Obstet Gyn 1997 ; 37 (1) : 112-114.

15. Hedajati H, Parsons J, Crowther C.A. Rectal analgesiafor pain from perineal trauma following child birth.(Cochrane Review). The Cochrane library issue 4. Chicheter, UK : Wiley 2003.

16. Corkhill A, Lavencler T, Walkinshaw SA, Alfreviz Z, Reducing postnatal pain from Perineal tears by using lignocaine gel: A double blind randomize trial. Birth 2001; 28(1) : 22- 27 